\title{
Chromato-Mass-Spectrometric Identification of Glycosides of Phenylethylamides of Hydroxycinnamic Acids in a Suspension Cell Culture of Mandragora turcomanica
}

\author{
D. V. Kochkin ${ }^{a, c, *}$, B. A. Galishev ${ }^{b}$, M. V. Titova ${ }^{c}$, E. V. Popova ${ }^{c}$, and A. M. Nosov ${ }^{a, c}$ \\ ${ }^{a}$ Faculty of Biology, Moscow State University, Moscow, Russia \\ ${ }^{b}$ Yeltsin Ural Federal University, Yekaterinburg, Russia \\ ${ }^{c}$ Timiryazev Institute of Plant Physiology, Russian Academy of Sciences, Moscow, Russia \\ *e-mail:dmitry-kochkin@mail.ru
}

Received July 30, 2020; revised December 25, 2020; accepted December 25, 2020

\begin{abstract}
A detailed UPLC-ESI-MS study was performed on secondary metabolites in the biomass of a suspension plant cell culture of Turkmenian mandrake (Mandragora turcomanica Mizgir.), which has been maintained for over 30 years. Both compounds widespread in plants (amides of hydroxycinnamic acids with putrescine and feruloyltyramine) and very rare metabolites (glycosides of phenylethylamides of hydroxycinnamic acids) have been identified. The identification of compounds was carried out using ultra-performance liquid chromatography combined with high-resolution mass spectrometry with electrospray ionization (UPLC-ESI-MS) and detection of positive and negative ion modes. Structural analysis of glycosides of phenylethylamides of ferulic acid was carried out on the basis of interpreting MS spectra obtained by fragmentation of protonated molecular ions $[\mathrm{M}+\mathrm{H}]^{+}$of these compounds in the ionization source. Based on the obtained results, the presence of five hexosides of ferulic acid, three of which were with tyramine residues and one each with methoxytyramine and octopamine residues, respectively, in the M. turcomanica cells cultivated in vitro was revealed. One of the detected glycosides belongs to a very rare group of plant metabolites: feruloyltyramine dihexosides. The obtained results confirm the concept developed in the authors' works on the change in specialized metabolism of plant cells cultivated in vitro and indicate that dedifferentiated proliferating cells retain the ability to form a complex set of secondary metabolites, which contradicts the prevailing ideas about the loss or decrease in the intensity of specialized metabolism in plant cell cultures.
\end{abstract}

Keywords: Mandragora turcomanica, suspension cell culture, tyramine, glycosides of phenylethylamides of ferulic acid, secondary metabolism

DOI: $10.1134 / \mathrm{S} 1021443721050083$

\section{INTRODUCTION}

Plants are among the most chemically complex organisms. The variable part of their composition is determined, first of all, by the formation and accumulation of substances of "specialized" metabolism (secondary metabolites), the role of which in the life of a plant is the subject of numerous discussions. Currently, the prevailing point of view is the participation of secondary metabolites in the interaction of a plant with the environment: the formation and regulation of bonds in various types of coexistence of plants with other organisms (symbiotic, antagonistic, and other variants of the relationship of organisms), the reaction of a plant organism to changes in abiotic environmental factors, etc. [1]. One of the promising approaches to elucidating the functional significance of secondary metabolism is its study in the plant cell culture, a unique biological system in which many biochemical processes (including secondary metab- olism) are implemented in a manner different from intact plants $[1,2]$. Comparing the patterns of specialized metabolism in plant cells in vivo and in vitro with knowledge of the specifics and conditions of their life allows one to draw well-grounded conclusions about the functional role of this process [1].

Currently, phytochemical study of plant cells in vitro is carried out in most cases by comparing the chromatographic profiles of extracts from the biomass of plant cell cultures with the chromatograms of standard samples of secondary metabolites characteristic of a particular plant (this strategy of phytochemical study of plant cell cultures can be conventionally designated as "classical") [2]. This approach does not allow detecting the entire spectrum of compounds formed in cell cultures, which, apparently, underlies the widespread opinion about the limitedness of specialized metabolism in plant cells in vitro [13]. At the same time, a thorough chemical study of plant cell cultures 
using the entire arsenal of phytochemical methods (various options for thin-layer chromatography, preparative isolation of individual compounds and description of their structure using NMR spectroscopy, etc.) indicates the possibility of the formation of uncharacteristic and/or "minor" (occurring rarely and in trace amounts) metabolites for intact plants, commercial standard samples of which are absent in the overwhelming majority of cases $[2,4]$. Thus, the "classical" strategy of phytochemical analysis does not always provide correct information on the diversity of secondary metabolites in plant cells in vitro.

The current stage in the development of phytochemistry is characterized by the active use of various types of chromatography-mass spectrometry in describing the structural diversity of secondary metabolites in intact plants [5]. In the most universal version, this experimental approach is based on the combined use of liquid chromatography (high- or ultra-performance-HPLC or UPLC, respectively) with quadrupole-time-of-flight mass spectrometry with electrospray ionization. Currently in scientific literature this experimental approach is referred to as LC-ESI-Q-TOF-MS (liquid chromatography electrospray ionization quadrupole time-of-flight mass spectrometry) [5]. The use of LC-ESI-Q-TOF-MS in phytochemical analysis has significantly expanded the understanding of the complexity of the chemical composition of plants. In one of the pioneering works in this direction, it was shown that LC-ESI-Q-TOF-MS allows the detection and structural description of more than 600 triterpene glycosides (ginsenosides) of various structures in various samples of ginseng (Panax spp.) [6]. At the same time, reliable structural identification of metabolites is possible, the content of which is vanishingly small: up to $10^{-4} \%$ of the dry weight of plant samples, which was confirmed using "classical" phytochemistry methods: preparative isolation of individual compounds and studying their structure using nuclear magnetic resonance (NMR) spectroscopy [6].

While LC-ESI-Q-TOF-MS-based methods are widely applied in biochemical studies in intact plants, they are still rarely utilized in biochemical analysis of in vitro cultured plant cells. Based on the foregoing, it can be assumed that the use of liquid chromatography-mass spectrometry, primarily LC-ESI-Q-TOF-MS, in the study of plant cell cultures will provide more objective information about the biochemical characteristics of this unique biological system and, therefore, such works have undoubted fundamental and applied value.

Mandragora (Mandragora spp.) is a genus of herbaceous perennial plants of the Solanaceae family. It is a legendary plant of medieval Europe, mentioned in the Bible. It has now been established that many of the properties of mandrake are due to the presence of tropane alkaloids: hyoscyamine, atropine, scopolamine, etc. [8-10].
The endemic species of the mountainous regions of southwest Turkmenistan Mandragora turcomanica Mizgir. was described in 1942 and is perhaps one of the rarest medicinal plants [8]. The natural population of $M$. turcomanica has only a several hundreds of plants left. Moreover, the specific biology of this species complicates its introduction, e.g. in botanic gardens, and/or plantation cultivation [8-10]. Therefore, induction and detailed study of $M$. turcomanica cell culture is of great practical and scientific value.

In 1981, cell culture of M. turcomanica was induced from a leaf explant by R.G. Butenko and N.A. Myasoedov at K.A. Timiryazev Institute of Plant Physiology (Russian Academy of Sciences) and has been maintained since then by periodic subcultures.

The aim of this work was the phytochemical study, using ultra-performance liquid chromatography, combined with high-resolution mass spectrometry with electrospray ionization (UPLC-ESI-MS, one of the variants of LC-ESI-Q-TOF-MS), of the biomass of a suspension cell culture of $M$. turcomanica maintained in culture in vitro over 30 years.

\section{MATERIALS AND METHODS}

Plant material. The object of the study was a heterotrophic suspension plant cell culture of Turkmenian mandrake (Mandragora turcomanica Mizgir.), which has been maintained in an growing state since 1981 in the All-Russian Collection of Plant Cell Cultures at the Institute of Plant Physiology, Russian Academy of Sciences under no. 31 [11].

Plant cell culture growing conditions. Cell culture of M. turcomanica was grown (in accordance with the collection passport) on a modified nutrient medium with a mineral base according to Murashige-Skoog [12] with the addition of glucose $(4 \%)$, thiamine $(1 \mathrm{mg} / \mathrm{L})$, $\alpha$-NAA $(3 \mathrm{mg} / \mathrm{L})$, and BAP $(0.5 \mathrm{mg} / \mathrm{L})$ [13]. The cultivation was carried out in the dark, at $26^{\circ} \mathrm{C}$, on rotary shaker $(90 \mathrm{rpm})$, in $250 \mathrm{~mL}$ flasks sealed with a double layer of aluminum foil and a layer of offset paper (30$40 \mathrm{~mL}$ of suspension in a flask). The subcultivation cycle was 2 weeks. For chemical analysis, biomass was used 10 days after subculture to a fresh medium (exponential phase of culture growth).

Sample preparation for UPLC-ESI-MS analysis. A weighed portion of air-dry plant material $(31 \mathrm{mg})$ was extracted three times with $1 \mathrm{~mL}$ of $70 \%$ (by volume) aqueous ethyl alcohol for $30 \mathrm{~min}$ under the action of ultrasound (UZV-12, Sapphire, Russia), after which it was centrifuged at $10000 \mathrm{rpm}$ for $10 \mathrm{~min}$ (Microcentrifuge MCF, Russia) and the supernatant was taken into a pear-shaped flask. The combined alcoholic extracts were evaporated under vacuum (at $55^{\circ} \mathrm{C}$ ). The obtained extract was suspended in $1 \mathrm{~mL}$ of distilled water and applied to a Supelclean ENVI-18 solid-phase extraction cartridge (Supelco, United States). The cartridge was washed with $3 \mathrm{~mL}$ of dis- 
tilled water, and the analytes were washed off with $3 \mathrm{~mL}$ of ethanol. The resulting solution was evaporated under vacuum at $55^{\circ} \mathrm{C}$. Before analysis, the extracts were dissolved in $1 \mathrm{~mL}$ of an acetonitrilewater mixture ( $1: 1$, by volume).

UPLC-ESI-MS. The analysis was performed on a Waters Acquity UPLC chromatograph (Waters, United States) equipped with a XEVO QTOF hybrid quadrupole time-of-flight mass spectrometer (Waters). A sample in a volume of $1 \mu \mathrm{L}$ was loaded onto an ACQUITY UPLC BEH Phenyl column $(50 \times 2.1 \mathrm{~mm}$, $1.7 \mu \mathrm{m}$; Waters, Ireland). The column temperature was $40^{\circ} \mathrm{C}$, the volumetric flow rate of the mobile phase was $0.4 \mathrm{~mL} / \mathrm{min}$. A $0.1 \%$ (by volume) solution of formic acid in water (solvent $\mathrm{A}$ ) and a $0.1 \%$ (by volume) solution of formic acid in acetonitrile (solvent B) were used as the mobile phase. Chromatographic separation was performed in the gradient elution mode. During the analysis, the composition of the mobile phase changed as follows (B, \% by volume): $15 \%$ at $0-$ $1 \mathrm{~min}$, from 15 to $30 \%$ at $1-5 \mathrm{~min}$, from 30 to $38 \%$ at $5-15 \mathrm{~min}$, from 38 to $45 \%$ at $15-15.5 \mathrm{~min}, 45 \%$ at $15.5-23 \mathrm{~min}$, and from 45 to $95 \%$ at $23-23.5 \mathrm{~min}$. The analysis was carried out in the mode of detecting positive and negative ions (range $m / z$ 100-2000). Ionization source parameters: $120^{\circ} \mathrm{C}$ ionization source temperature, $250^{\circ} \mathrm{C}$ desolvation temperature, $3.0 \mathrm{kV}$ capillary voltage, $30 \mathrm{~V}$ sample injection cone voltage, $600 \mathrm{~L} / \mathrm{h}$ nitrogen (desolvation gas) flow rate. The results were processed using the MassLynx software (Waters).

\section{RESULTS}

At the first stage of the work, we carried out the UPLC-ESI-MS analysis of the alcohol extract from the biomass of the suspension cell culture of M. turcomanica in the mode of detecting positively charged ions. The choice of this mode is due to the fact that fragmentation is observed (with the formation of characteristic fragment ions) already in the ionization source during ionization by electrospray for positively charged ions (primarily, protonated molecules $\left([\mathrm{M}+\mathrm{H}]^{+}\right)$) of many natural compounds $[14,15]$. The analysis of the mass spectra obtained in this way makes it possible to carry out a fairly rapid primary structural identification of compounds without performing additional tandem mass spectrometric experiments [15]. For chromatographic separation, we used a gradient elution program developed earlier for the analysis of natural compounds of a wide range of polarity on chromatographic columns with reversed phase [15].

The resulting UPLC-ESI-MS chromatogram (total ion current) is shown in Fig. 1. In total in biomass extract of M. turcomanica cell suspension culture, we found nine chromatographic peaks of compounds (eluted from the chromatographic column within $0.5-$ $4.0 \mathrm{~min}$ ), which were numbered from 1 to 9 in order of

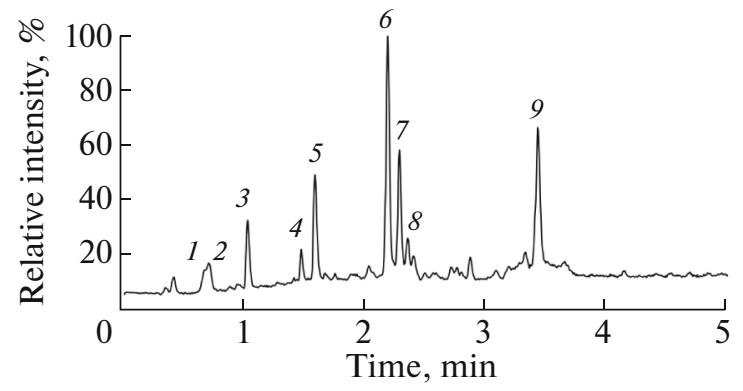

Fig. 1. UPLC-ESI-MS chromatogram (recorded in total ion current mode when registering positive ions) of an extract from the biomass of a cell suspension culture M. turcomanica (line 31, day 10 of subculture cycle). Numbers (1-9) are peaks of identified compounds (Tables 1, 2).

increasing retention time on the chromatographic column.

For the structural identification of the detected compounds, the following information was used: interpretation of the results of mass spectrometry (fragmentation of protonated molecules of compounds in the ionization source), determination (based on comparison of the calculated and experimentally measured values of the exact monoisotopic molecular weight) of the elemental composition of compounds [16] and comparison of mass spectrometric and relative chromatographic behavior of compounds with literature data [17-22]. The data of mass spectra and the results of identification of the detected compounds are presented in Table 1.

General analysis of the mass spectra of positive ions of the detected compounds (Table 1) suggests that they all belong to the group of hydroxycinnamic acid amides [17]. Based on structural features, these metabolites can be divided into four groups: metabolites $1-3$, derivatives of aliphatic diamine putrescine, acylated with hydroxycinnamic acid residues; metabolite 9 , ferulic acid amide with aromatic monoamine tyramine; metabolites $5-8$, hexosides of ferulic acid amides with tyramine (metabolites 5-7) and methoxytyramine (metabolite 8 ); metabolite 4 , ferulic acid amide hexoside with aromatic monoamine octopamine (contains a hydroxyl group in the aliphatic part of monoamine). For the mass spectra of positive ions of each of these groups of compounds, certain features are noted.

In mass spectra of positive ions of metabolites $1-3$, three intense signals are present: the ion of the protonated molecule $[\mathrm{M}+\mathrm{H}]^{+}$(the validity of the identification of this ion is confirmed by the presence of the adduct ion $[\mathrm{M}+\mathrm{Na}]^{+}$) and two fragment ions formed as a result of a neutral loss of $17 \mathrm{Da}$ (elimination of the terminal amino group (in the form of $\mathrm{NH}_{3}$, ion $[\mathrm{M}+\mathrm{H}-17]^{+}$) the putrescine residue) and $88 \mathrm{Da}$ (cleavage of the whole putrescine residue, $\mathrm{C}_{4} \mathrm{H}_{12} \mathrm{~N}_{2}$, ion $[\mathrm{M}+\mathrm{H}-88]^{+}$). Characteristic ion 
KOCHKIN et al.

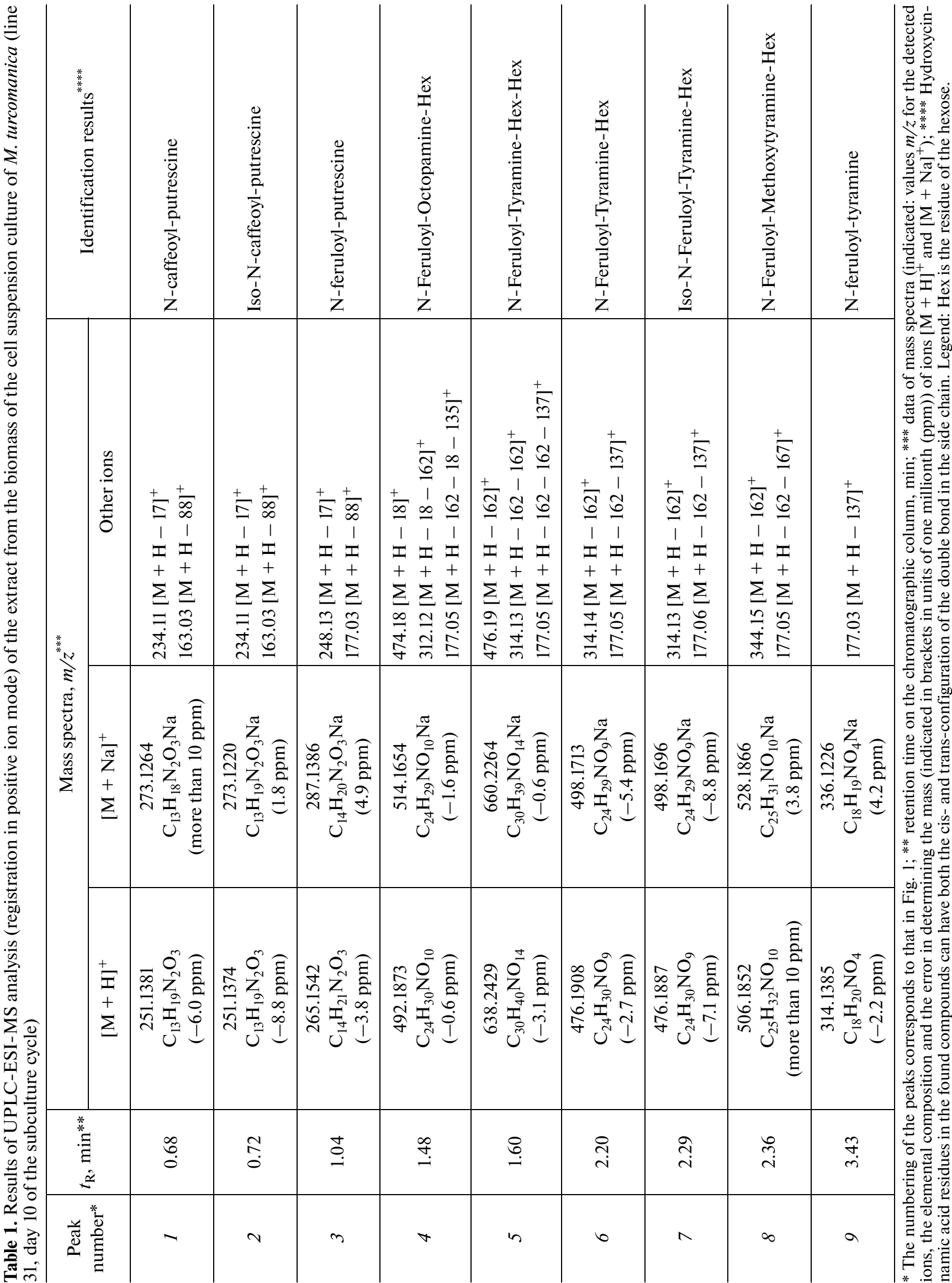


$[\mathrm{M}+\mathrm{H}-88]^{+}$corresponds to the residue of hydroxycinnamic acid acylating one of the amino groups of putrescine: for compounds 1 and 2, this ion is $m / z 163$ (characteristic ion of caffeic acid residue, $\mathrm{C}_{9} \mathrm{H}_{7} \mathrm{O}_{3}{ }^{+}$); that for compound 3 is $m / z, 177$ (characteristic ion of ferulic acid residue, $\mathrm{C}_{10} \mathrm{H}_{9} \mathrm{O}_{3}{ }^{+}$). Thus, metabolites 1 , 2 , and 3 , most likely, have the structure of putrescine acylated with caffeic (metabolites 1 and 2 ) and ferulic (metabolite 3) acid residues. The described fragmentation pattern in the ionization source $[\mathrm{M}+\mathrm{H}]^{+}$of these compounds are in good agreement with the literature data $[17,21]$.

In the mass spectrum of the compound 9 , there are two strong signals: $[\mathrm{M}+\mathrm{H}]^{+}$and a fragmentation characteristic ion $(\mathrm{m} / z \mathrm{177})$ corresponding to the ferulic acid residue. Difference between values $m / z$ of these ions corresponds to a neutral loss of the tyramine residue (neutral loss of $137 \mathrm{Da}, \mathrm{C}_{8} \mathrm{H}_{11} \mathrm{NO}$ ) [17, 18, 22]. Based on these results, the compound 9 is identified as an amide of ferulic acid and tyramine.

Fragmentation in the ionization source of protonated molecules $[\mathrm{M}+\mathrm{H}]^{+}$of compounds $5-8$ is accompanied by the formation of a series of fragment ions corresponding to the sequential elimination of one or two residues of dehydrated hexose (neutral loss of $162 \mathrm{Da}, \mathrm{C}_{6} \mathrm{H}_{10} \mathrm{O}_{5}$ ). In the mass spectra of positive ions of compounds $5-8$, there is a characteristic ion with $m / z$ 177. Analysis of the patterns of fragmentation of these metabolites also allows us to conclude that tyramine appears as an "amino component" in compounds 5-7 (neutral loss of $137 \mathrm{Da}$ ) and methoxytyramine is in compound 8 (neutral loss $167 \mathrm{Da}$, $\mathrm{C}_{9} \mathrm{H}_{13} \mathrm{NO}_{2}$ ). Thus, based on the above results, it can be assumed that the compounds 5-8 correspond to glycosides (more precisely, hexosides) of ferulic acid amides with tyramine/methoxytyramine. Based on the data of mass spectrometry alone, it is impossible to establish exactly which monosaccharides correspond to the residues of hexoses found in the composition of the compounds $5-8[17,22]$. Plants contain feruloyltyramine hexosides with glucopyranose, galactopyranose, or allopyranose [17, 20, 22, 23]. In addition, on the basis of the obtained mass spectra, it is impossible to draw conclusions about the glycosylation position: the hydroxyl group of hydroxycinnamic acid or monoamine (in plants, both variants of attachment of carbohydrate chains to ferulic acid phenylethylamides are found) [17, 24, 25]. The question on the configuration of the double bond (both cis and trans isomers occur in nature) of the ferulic acid residue also remains unresolved $[17,24]$. More research is required to clarify these elements of the structure of compounds $5-8$.

A feature of the mass spectrum of positive ions of the compound 4 (in comparison with mass spectra of compounds $5-8$ ) is the presence of an intensive ion: the product of the elimination of the rest of water (neutral loss of $18 \mathrm{Da}$ ) directly from the protonated molecule $[\mathrm{M}+\mathrm{H}]^{+}$. The mass spectrum also contains fragment ions formed as a result of neutral loss of the hexose residue and a characteristic ion with $m / z 177$. Taken together, the results presented suggest that the compound 4 corresponds to hexoside of ferulic acid amide with monoamine octopamine (contains a hydroxyl group in the aliphatic part of the monoamine molecule; the presence of two neutral losses $18 \mathrm{Da}$ and $135 \mathrm{Da}\left(\mathrm{H}_{2} \mathrm{O}\right.$ and $\mathrm{C}_{8} \mathrm{H}_{9} \mathrm{NO}$, respectively)) [18].

The validity for the interpretation of the mass spectra of positive ions in compounds $1-9$ is confirmed by the results of the UPLC-ESI-MS analysis of the alcohol extract from the biomass of the suspension cell culture M. turcomanica in the mode of detecting negatively charged ions (Table 2 ).

\section{DISCUSSION}

The amides of hydroxycinnamic acids with putrescine (components 1-3) identified in the biomass of the cell suspension culture $M$. turcomanica are quite widespread in plants and are currently considered as storage forms involved in the regulation of homeostasis of this diamine in plant cells [26, 27]. Feruloyltyramine (component 9) belongs to a small group of phenylethylamides of hydroxycinnamic acids widespread in plants: inducible metabolites involved in the biochemical reactions of plants to the effect of stress factors of various nature as well as precursors of a wide class of lignanamides [26]. At the same time, glycosides of ferulic acid phenylethylamides (components 4-8; Fig. 2) found in cultivated in vitro $M$. turcomanica cells belong to one of the rarest groups of secondary plant metabolites. Indeed, while the patterns of distribution and biosynthesis of phenylethylamides of hydroxycinnamic acids have been studied in sufficient detail and are summarized with enviable frequency in review articles [26, 27], the structural diversity of their conjugates with sugar residues has not been studied as well. Currently, approximately ten monohexosides (glucosides, galactosides, and allosides) of hydroxycinnamic acid phenylethylamides have been isolated from plants, while only a single structure is described for the dihexosides of these compounds (a similar metabolite was identified in this work (compound 5) [20, 23-25, 28]. Glycosides of phenylethylamides of hydroxycinnamic acids are sporadically distributed in the plant world (their presence was recorded in representatives of the families Amaranthaceae/Chenopodiaceae, Aristolochiaceae, Menispermaceae, Papaveraceae, Ranunculaceae and Solanaceae) and accumulate in plant tissues in trace amounts, their content in plants rarely exceed $0.0008 \%$ of dry weight) [20, 23-25, 28, 29]. The data available in the literature suggests that glycosides of hydroxycinnamic acid phenylethylamides may have storage and/or transport function of in plant cells [29, 30]. 
Table 2. Results of UPLC-ESI-MS analysis (registration in negative ion mode) of an extract from the biomass of a suspension cell culture $M$. turcomanica (line 31, day 10 of the subculture cycle in flasks)

\begin{tabular}{|c|c|c|c|c|}
\hline \multirow{2}{*}{$\begin{array}{c}\text { Peak } \\
\text { number* }\end{array}$} & \multirow{2}{*}{$t_{\mathrm{R}}, \min * *$} & \multicolumn{2}{|r|}{ Mass spectra, $m / z^{* * *}$} & \multirow{2}{*}{ Identification results $* * * *$} \\
\hline & & {$[\mathrm{M}-\mathrm{H}]^{-}$} & Other ions & \\
\hline 1 & 0.68 & 249.12 & $499.25[2 \mathrm{M}-\mathrm{H}]^{-}$ & N-caffeoyl-putrescine \\
\hline 2 & 0.72 & 249.12 & $499.26[2 \mathrm{M}-\mathrm{H}]^{-}$ & Iso-N-caffeoyl-putrescine \\
\hline 3 & 1.04 & 263.16 & - & $\mathrm{N}$-feruloyl-putrescine \\
\hline 4 & 1.48 & 490.16 & $\begin{array}{l}981.34[2 \mathrm{M}-\mathrm{H}]^{-} \\
328.12[\mathrm{M}-\mathrm{H}-162]^{-}\end{array}$ & N-Feruloyl-Octopamine-Hex \\
\hline 5 & 1.60 & 636.21 & $\begin{array}{l}1273.46[2 \mathrm{M}-\mathrm{H}]^{-} \\
1319.47\left[2 \mathrm{M}-\mathrm{H}+\mathrm{HCOOH}^{-}\right. \\
474.16[\mathrm{M}-\mathrm{H}-162]^{-}\end{array}$ & N-Feruloyl-Tyramine-Hex-Hex \\
\hline 6 & 2.20 & 474.17 & $\begin{array}{l}1424.53[3 \mathrm{M}-\mathrm{H}]^{-} \\
949.34[2 \mathrm{M}-\mathrm{H}]^{-} \\
995.37[2 \mathrm{M}-\mathrm{H}+\mathrm{HCOOH}]^{-} \\
312.12[\mathrm{M}-\mathrm{H}-162]^{-} \\
520.18[\mathrm{M}-\mathrm{H}+\mathrm{HCOOH}]^{-} \\
542.16\left[\mathrm{M}-\mathrm{H}+\mathrm{HCOONa}^{-}\right. \\
537.16\left[\mathrm{M}-\mathrm{H}+\mathrm{HCOONH}_{4}\right]^{-}\end{array}$ & N-Feruloyl-Tyramine-Hex \\
\hline 7 & 2.29 & 474.17 & $\begin{array}{l}949.34[2 \mathrm{M}-\mathrm{H}]^{-} \\
312.12[\mathrm{M}-\mathrm{H}-162]^{-} \\
542.16\left[\mathrm{M}-\mathrm{H}+\mathrm{HCOONa}^{-}\right. \\
537.17\left[\mathrm{M}-\mathrm{H}+\mathrm{HCOONH}_{4}\right]^{-}\end{array}$ & Iso-N-Feruloyl-Tyramine-Hex \\
\hline 8 & 2.36 & 504.18 & $\begin{array}{l}1009.38[2 \mathrm{M}-\mathrm{H}]^{-} \\
342.13[\mathrm{M}-\mathrm{H}-162]^{-} \\
572.17\left[\mathrm{M}-\mathrm{H}+\mathrm{HCOONa}^{-}\right. \\
567.19\left[\mathrm{M}-\mathrm{H}+\mathrm{HCOONH}_{4}\right]^{-}\end{array}$ & N-Feruloyl-Methoxytyramine-Hex \\
\hline 9 & 3.43 & 312.12 & $\begin{array}{l}625.25[2 \mathrm{M}-\mathrm{H}]^{-} \\
380.11[\mathrm{M}-\mathrm{H}+\mathrm{HCOONa}]^{-}\end{array}$ & N-feruloyl-tyramine \\
\hline
\end{tabular}

* Numbering of peaks corresponds to that in Table $1 ;{ }^{* *}$ retention time on the chromatographic column, min; ${ }^{* * *}$ data of mass spectra (values are indicated $\mathrm{m} / \mathrm{z}$ for detected ions); ${ }^{* * * *}$ Hydroxycinnamic acid residues in the found compounds can have both the cis- and trans-configuration of the double bond in the side chain. Legend: Hex is the residue of the hexose.

It should be emphasized that all compounds described in this work were found for the species M. turcomanica for the first time; however, additional research is required for their more accurate structural identification.

It is important to note that, in the present study, it was not possible to detect secondary metabolitestropane alkaloids, coumarins, and/or vitanolidestypical for plants of the genus Mandragora spp. (and many other members of the Solanaceae family) in the biomass of the suspension culture of $M$. turcomanica cells [10].
Thus, in this work we carried out for the first time a detailed-UPLC-mass spectrometric study of secondary metabolites in the biomass of a suspension plant cell culture of $M$. turcomanica. Both compounds widespread in plants (amides of hydroxycinnamic acids with putrescine and feruloyltyramine) and very rare metabolites (glycosides of phenylethylamides of hydroxycinnamic acids) were identified. It is important that a significant structural diversity of glycosylated hydroxycinnamic acid phenylethylamides was found in the biomass of a suspension cell culture of M. turcomanica, which has been maintained in active 
<smiles>[R20]c1ccc(C(O)CNC(=O)/C=C/c2ccc([R20])c(OC)c2)cc1</smiles><smiles>COc1ccc(C=CC(=O)NCCc2ccc(O)cc2)cc1O</smiles><smiles>[R20]Oc1ccc(CCNC(=O)/C=C/c2ccc([R20])c(OC)c2)cc1</smiles><smiles>[R]c1ccc(/C=C/C(=O)NCCc2ccc([R20])c(OC)c2)cc1OC</smiles>

Fig. 2. Structures of the identified (based on the results of UPLC-ESI-MS) glycosides of phenylethylamides of ferulic acid from the biomass of a suspension culture of M. turcomanica cells. Legend: R-H or Hex. Hex is the residue of the hexose.

growth for over 30 years [11]. This result indicates the preservation in long-term cultivated in vitro plant cells of the ability to form a very complex set of secondary metabolites and contradicts the prevailing concepts [3] about the patterns of specialized metabolism in plant cell cultures.

\section{ACKNOWLEDGMENTS}

The work on growing the cell culture was carried out using the equipment of the Scientific and Production Complex Based on the Development of Nature-Saving Hi-Tech Biotechnology for Obtaining High-Quality Raw Materials for Pharmaceutical and Food Purposes Using Cultured Cells and Organs of Higher Plants or Microalgae, including the equipment of the Unique Scientific Installations AllRussia Collection of Cell Cultures of Higher Plants and the Experimental Biotechnological Complex of the Timiryazev Institute of Plant Physiology of the Russian Academy of Sciences (UNU OBK IGF RAS and UNU VRKKK BP IGF RAS) with financial support from the Megagrant of the Government of the Russian Federation (agreement no. 075-15-2019-1882).

\section{FUNDING}

The work on the analysis of the biochemical composition of the cell culture was carried out with the financial support of the Russian Foundation for Basic Research (project no. 18-54-06021 Az_a).

\section{RUSSIAN JOURNAL OF PLANT PHYSIOLOGY Vol. 68}

\section{COMPLIANCE WITH ETHICAL STANDARDS}

Conflict of interests. The authors declare that they have no conflicts of interest.

Statement on the welfare of humans or animals. This article does not contain any studies involving humans or animals performed by any of the authors.

\section{OPEN ACCESS}

This article is licensed under a Creative Commons Attribution 4.0 International License, which permits use, sharing, adaptation, distribution and reproduction in any medium or format, as long as you give appropriate credit to the original author(s) and the source, provide a link to the Creative Commons license, and indicate if changes were made. The images or other third party material in this article are included in the article's Creative Commons license, unless indicated otherwise in a credit line to the material. If material is not included in the article's Creative Commons license and your intended use is not permitted by statutory regulation or exceeds the permitted use, you will need to obtain permission directly from the copyright holder. To view a copy of this license, visit http://creativecommons.org/licenses/by/4.0/.

\section{REFERENCES}

1. Nosov, A.M., Functions of plant secondary metabolites in vivo and in vitro, Russ. J. Plant Physiol., 1994, vol. 41, p. 767.

2. Nosov, A.M., Popova E.V., and Kochkin D.V., Isoprenoid production via plant cell cultures: biosynthesis, accumulation and scaling-up to bioreactors, in Produc-

No. 52021 
tion of Biomass and Bioactive Compounds Using Bioreactor Technology, Paek, K.-Y., , Eds., Dordrecht: Springer-Verlag, 2014, p. 563.

3. Ramachandra Rao, S. and Ravishankar, G.A., Plant cell cultures: chemical factories of secondary metabolites, Biotechnol. Adv., 2002, vol. 20, p. 101.

4. Kochkin, D.V., Globa, E.B., Demidova, E.V., Gaisinsky, V.V., Kuznetsov, V.V., and Nosov, A.M., Detection of taxuyunnanin $\mathrm{C}$ in suspension cell culture of Taxus canadensis, Dokl. Biochem. Biophys., 2019, vol. 485, p. 129.

5. Dettmer, K., Aronov, P.A., and Hammock, B.D., Mass spectrometry-based metabolomics, Mass Spectrom. Rev., 2007, vol. 26, p. 51.

6. Yang, W.Z., Ye, M., Qiao, X., Liu, C.F., Miao, W.J., Bo, T., Tao, H.Y., and Guo, D.A., A strategy for efficient discovery of new natural compounds by integrating orthogonal column chromatography and liquid chromatography/mass spectrometry analysis: its application in Panax ginseng, Panax quinquefolium and $\mathrm{Pa}$ nax notoginseng to characterize 437 potential new ginsenosides, Anal. Chim. Acta, 2012, vol. 739, p. 56.

7. Chun, S.C., Gopal, J., Iyyakannu, S., and Muthu, M., An analytical retrospection of mass spectrometric tools established for plant tissue culture: current endeavors and future perspectives, TrAC, Trends Anal. Chem., 2020, vol. 126, p. 115843 . https://doi.org/10.1016/j.trac.2020.115843

8. Akhani, H. and Ghorbani, A.B., Mandragora turcomanica (Solanaceae) in Iran: a new distribution record for an endangered species, Syst. Biodiversity, 2003, vol. 1, p. 177.

9. Sinev, I.E., The history of Mandragora turkomanica (Solanaceae), Isr. J. Plant Sci., 2016, vol. 63, p. 176.

10. Hanuš, L.O., Rezanka, T., Spížek, J., and Dembitsky, V.M., Substances isolated from Mandragora species, Phytochemistry, 2005, vol. 66, p. 2408.

11. Pakhlavouni, I.K., Khaibullina, L.A., and Serebryakova, V.N., Carotenoid composition and chloroplast ultrastructure in two cell lines of Mandragora turcomanica (Solanaceae), Russ. J. Plant Physiol., 2000, vol. 47, p. 38.

12. Murashige, T. and Skoog, F., A revised medium for rapid growth and bio assays with tobacco tissue cultures, Physiol. Plant., 1962, vol. 15, p. 473.

13. Mandragora turcomanica Mizgir.: Pasport Vserossiiskoi kollektsii rastitel'nykh kletok $i$ organov vysshikh rastenii (Mandragora turcomanica Mizgir.: Passport of the AllRussian Collection of Cell and Organ Cultures of Higher Plants), Moscow: Inst. Fiziol. Rast., Ross. Akad. Nauk, 1984.

14. Abrankó, L., García-Reyes, J.F., and Molina-Díaz, A., In-source fragmentation and accurate mass analysis of multiclass flavonoid conjugates by electrospray ionization time-of-flight mass spectrometry, J. Mass Spectrom., 2011, vol. 46, p. 478.

15. Kochkin, D.V., Galishev, B.A., Glagoleva, E.S., Titova, M.V., and Nosov, A.M., Rare triterpene glycoside of ginseng (ginsenoside malonyl-Rg1) detected in plant cell suspension culture of Panax japonicus var. repens, Russ. J. Plant Physiol., 2017, vol. 64, p. 649.

16. Brenton, A.G. and Godfrey, A.R., Accurate mass measurement: terminology and treatment of data, J. Am. Soc. Mass Spectrom., 2010, vol. 21, p. 1821.

17. Nikolić, D., Gödecke, T., Chen, S.-N., White, J., Lankin, D.C., Pauli, G.F., and van Breemen, R.B., Mass spectrometric dereplication of nitrogen-containing constituents of black cohosh (Cimicifuga racemosa L.), Fitoterapia, 2012, vol. 83, p. 441.
18. Zhang, J., Guan, S., Sun, J., Liu, T., Chen, P., Feng, R., Chen, X., Wu, W., Yang, M., and Guo, D.A., Characterization and profiling of phenolic amides from Cortex lycii by ultra-high performance liquid chromatography coupled with LTQ-Orbitrap mass spectrometry, Anal. Bioanal. Chem., 2015, vol. 407, p. 581.

19. Li, Z., Zhao, C., Zhao, X., Xia, Y., Sun, X., Xie, W., Ye, Y., Lu, X., and Xu, G., Deep annotation of hydroxycinnamic acid amides in plants based on ultrahigh-performance liquid chromatography-high-resolution mass spectrometry and it's in silico database, Anal. Chem., 2018, vol. 90, p. 14321.

20. Yim, S.-H., Kim, H., Jeong, N., Deok, K., Lee, Y.J., Cho, S., and Lee, I.-S., Novel phenolic and phenolic amide allosides structure-guided identification of novel phenolic and phenolic amide allosides from the rhizomes of Cimicifuga heracleifolia, Bull. Korean Chem. Soc., 2012, vol. 33, p. 1253.

21. Sun, J., Song, Y.L., Zhang, J., Huang, Z., Huo, H.X., Zheng, J., Zhang, Q., Zhao, Y.F., Li, J., and Tu, P.F., Characterization and quantitative analysis of phenylpropanoid amides in eggplant (Solanum melongena L.) by high performance liquid chromatography coupled with diode array detection and hybrid ion trap time-offlight mass spectrometry, J. Agric. Food Chem., 2015 , vol. 63 , p. 3426 .

22. Geng, P., Harnly, J.M., Sun, J., Zhang, M., and Chen, P., Feruloyl dopamine-O-hexosides are efficient marker compounds as orthogonal validation for authentication of black cohosh (Actaea racemosa)-an UHPLCHRAM-MS chemometrics study, Anal. Bioanal. Chem., 2017, vol. 409, p. 2591.

23. Zhang, F., Han, L.-F., Pan, G.-X., Peng, S., and Ndagijimana, A., A new phenolic amide glycoside from Cimicifuga dahurica, Acta Pharm. Sin., 2013, vol. 48, p. 1281.

24. Yahagi, T., Yamashita, Y., Daikonnya, A., Wu, J.B. and Kitanaka, S., New feruloyl tyramine glycosides from Stephania hispidula Yamamoto, Chem. Pharm. Bull., 2010, vol. 58, p. 415.

25. Yang, L., Jiang, H., Wang, Q.H., Yang, B.Y., and Kuang, H.X., A new feruloyl tyramine glycoside from the roots of Achyranthes bidentata, Chin. J. Nat. Med., 2012, vol. 10, p. 16.

26. Bassard, J.E., Ullmann, P., Bernier, F., and WerckReichhart, D., Phenolamides: bridging polyamines to the phenolic metabolism, Phytochemistry, 2010, vol. 71, p. 1808.

27. Edreva A.M., Velikova V.B., and Tsonev T.D., Phenylamides in plants, Russ. J. Plant Physiol., 2007, vol. 54, p. 287.

28. Wu, P.L., Su, G.C., and Wu, T.S., Constituents from the stems of Aristolochia manshuriensis, J. Nat. Prod., 2003, vol. 66, p. 996.

29. Sun, G., Strebl, M., Merz, M., Blamberg, R., Huang, F.C., McGraphery, K., Hoffmann, T., and Schwab, W., Glucosylation of the phytoalexin N-feruloyl tyramine modulates the levels of pathogen-responsive metabolites in Nicotiana benthamiana, Plant J., 2019, vol. 100, p. 20.

30. Mhlongo, M.I., Piater, L.A., Madala, N.E., Steenkamp, P.A., and Dubery, I.A., Phenylpropanoid defences in Nicotiana tabacum cells: overlapping metabolomes indicate common aspects to priming responses induced by lipopolysaccharides, chitosan and flagellin-22, PLoS One, 2016, vol. 11, p. e0151350. https://doi.org/10.1371/journal.pone.0151350 